Article

\title{
Development of Bio-Sourced Epoxies for Bio-Composites
}

\author{
Xiao-Su Yi ${ }^{1,2, *}$, Xvfeng Zhang ${ }^{2,+}$, Fangbo Ding ${ }^{3,+}$ and Jianfeng Tong ${ }^{2, \dagger}$ \\ 1 Advanced Materials and Composites Department, Faculty of Science \& Engineering, \\ University of Nottingham (UNNC), Ningbo 315100, China \\ 2 AVIC Composite Corporation Ltd. (ACC), Beijing 101300, China; 010xufeng@sina.com (X.Z.); \\ broadtj@@sina.com (J.T.) \\ 3 AVIC XAC, Commercial Aircraft Co., Ltd., Xi'an 710000, China; dingfangbo313@163.com \\ * Correspondence: xiaosu.yi@nottingham.edu.cn; Tel.: +86-574-8818-0000 (ext. 8746) \\ + These authors contributed equally to this work.
}

Received: 22 April 2018; Accepted: 11 June 2018; Published: 15 June 2018

\begin{abstract}
In the air and ground transportation sectors, new environmental regulations and societal concerns have triggered a search for new products and processes that complement resources and the environment. To address these issues, this article reports on current R\&D efforts to develop bio-sourced materials by an international joint project. Novel bio-sourced epoxies and biocomposites were developed, characterized, modified and evaluated in terms of the mechanical property levels. Quasi-structural composite parts were finally trial-manufactured and demonstrated.
\end{abstract}

Keywords: rosin acid; itaconic acid; bio-sourced epoxy; bio-composites

\section{Introduction}

With the present state of composite technological development, biocomposites are understood as composites that consist of biopolymer matrices, i.e., bio-sourced resins and/or natural fiber reinforcements, e.g., plant fibers (PF) [1,2]. Besides existing applications in automobiles [3], this new member of the material family may provide an economical and environmentally-friendly alternative to glass-fiber-reinforced composites for quasi-structural applications in aircraft. The present paper provides an overview on the current development of biocomposite materials by an international joint project, ECO-COMPASS (Ecological and Multifunctional Composites for Application in Aircraft Interior and Secondary Structures, 2016-2019) [4], which is co-funded by the Chinese Ministry of Industry and Information Technology (MIIT) and the European Union, but with a special emphasis on bio-sourced epoxies and biocomposites. Quasi-structural composite parts were finally trial-manufactured and demonstrated using the epoxies as matrix resins.

\section{Rosin-Sourced Epoxy as a Matrix Resin}

Rosin is an abundantly available natural product, it is nontoxic and odorless, and contains various isomerized acids ( $>90 \%)$ and some neutral substances [5]. Reactive double bonds and carboxyl groups of rosin acids render them suitable for the Diels-Alder reaction, esterification and condensation reaction usage. Therefore, rosin acid has received increasing attention as a bio-sourced form of renewable feedstock in polymer science.

Anhydride is one of the curing agents for epoxies (EPs). Owing to their characteristic bulky hydrogenated phenanthrene ring structure, rosin acids are analogous to many aromatic compounds in rigidity. However, their curing temperature is generally high, about $200-250{ }^{\circ} \mathrm{C}$, and the curing time is long, which limits the use of the anhydride in some products and apparatus. The complex reactions 
of epoxy/anhydride curing include the carboxyl group reaction with an epoxy ring in the catalyzed action of accelerator, alternate ring-opening copolymerization of epoxy, and anhydride catalyzed by amine and polyetherification at high temperatures, initiated by amine and catalyzed by hydroxyl groups [6]. These processes occur when an amine is added as the catalyst. An excellent reference [6] on this issue can be found in the literature.

In this study $[7,8]$, an anhydride-type epoxy curing agent, maleopimaric (Scheme 1), was synthesized as a hardener from rosin acid (Scheme 1). This was supplied by the Ningbo Institute of Materials and Technology Engineering. A resin mixed with an E51-type epoxy and a solid phenolic epoxy was then prepared as the main component, together with an accelerator mixed of two amino imidazole salts as the thermally latent curing agent and also as the catalyst for the anhydride. The experimental details can also be find in reference [7]. Figure 1 exhibits the glass transition behavior of the formulated resin system. As shown, the curing degree increased with the curing temperature for a constant curing time of $3 \mathrm{~h}$, as well as the glass transition temperature. The formulated matrix resin was finally designated as AGMP3600, with a bio-content of about $30 \%$.

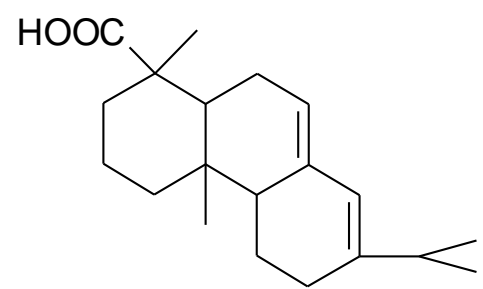

Abietic acid

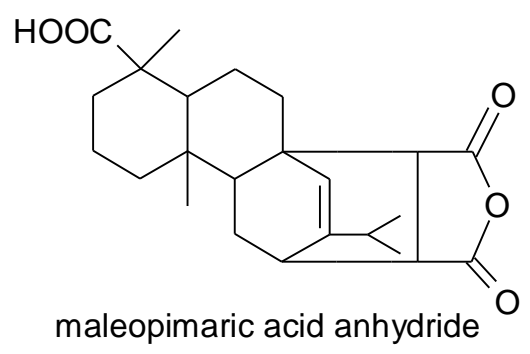

maleopimaric acid anhydride

Scheme 1. Structure formula of abietic acid and maleopimaric acid anhydride.

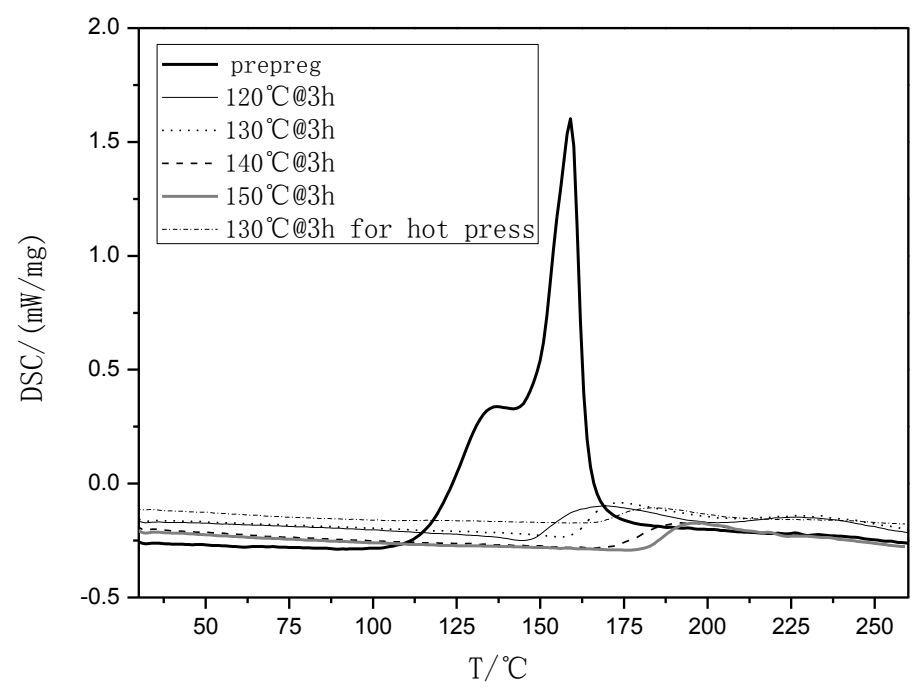

Figure 1. Differential Scanning Calorimetry (DSC) curves of the rosin-sourced epoxy resin system designated as AGMP3600 at different temperature conditions.

Figure 2 shows the typical viscosity behavior of the trial product AGMP3600. It behaved well in the film manufacturing and subsequent prepreg production. The process condition for the prepreg using AGMP3600 as the matrix in the autoclave is shown in Figure 3.

The mechanical properties of AGMP 3600 laminates reinforced with different kinds of fibers and weaves were determined and are listed in Tables $1-4$ in some cases compared with the state-of-the-art counterparts as reference. 


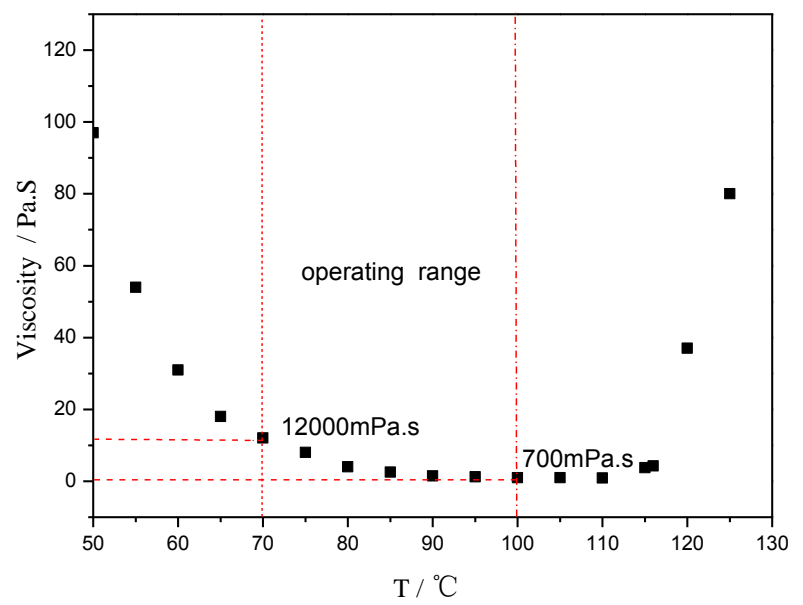

Figure 2. Viscosity vs. temperature of AGMP3600, a rosin-sourced epoxy resin system.

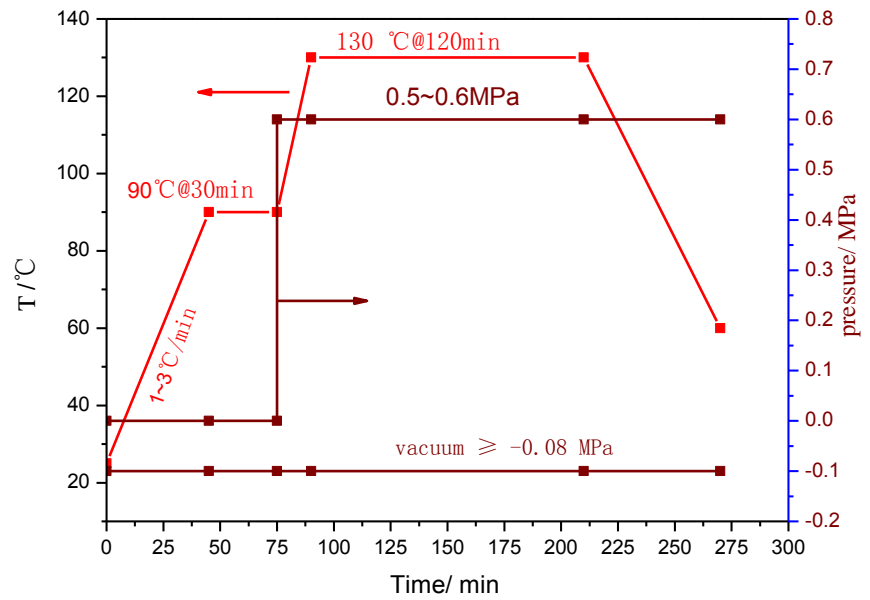

Figure 3. Process parameters for the curing of AGMP3600 prepreg in an autoclave.

Table 1. Mechanical properties of AGMP3600/EW250F (glass fabric, 8 satin, 47 vol \%), a rosin-sourced epoxy laminates, and of 3233B/EW250F, a standard intermediate-temperature epoxy laminate for reference and comparison.

\begin{tabular}{cccc}
\hline Properties & UNIT & 3233B/EW250F & AGMP3600/EW250F \\
\hline Ply thickness & $\mathrm{mm}$ & 0.241 & 0.237 \\
Bending strength & $\mathrm{MPa}$ & 696 & 674 \\
Bending modulus & $\mathrm{GPa}$ & 19.9 & 21.1 \\
Short beam shear strength & $\mathrm{MPa}$ & 45 & 60.9 \\
Tensile strength & $\mathrm{MPa}$ & 470 & 540 \\
Tensile modulus & $\mathrm{GPa}$ & 22.5 & 25.3 \\
Compression strength & $\mathrm{MPa}$ & 474 & 483 \\
Compression modulus & $\mathrm{GPa}$ & 23.9 & 27 \\
\hline
\end{tabular}

In parallel, a $180{ }^{\circ} \mathrm{C} / 2 \mathrm{~h}$ cured-rosin epoxy was also developed, designated as AGMP5600, with a higher bio-content of about $40 \%$. It is particularly interesting to note that the glass transition temperature of AGMP5600 matrix composite reinforced with EW250F glass weave was about $220{ }^{\circ} \mathrm{C}$. Table 4 lists the mechanical properties of the laminated composite. The temperaturedependent mechanical properties were also studied, as well as those after the hot/wet exposure (1000 h/70 ${ }^{\circ} \mathrm{C} / 85 \%$ r.H.) 
Table 2. Mechanical properties of AGMP3600/CW3011 (carbon fiber plain weave, $200 \mathrm{~g} / \mathrm{m}^{2}$, $57 \mathrm{vol} \%$ ), a rosin-epoxy laminate, and a corresponding reference laminate for comparison.

\begin{tabular}{|c|c|c|c|c|c|}
\hline \multicolumn{2}{|c|}{ Property and Test Condition } & \multirow{2}{*}{$\begin{array}{l}\text { Unit } \\
\mathrm{MPa}\end{array}$} & \multirow{2}{*}{$\begin{array}{c}\text { Reference }^{\mathbf{1}} \\
\geq 500\end{array}$} & \multirow{2}{*}{$\begin{array}{c}\text { Test Result } \\
707\end{array}$} & \multirow[t]{2}{*}{ Standard } \\
\hline Tensile strength warp & RT/dry & & & & \\
\hline Tensile modulus warp & RT/dry & $\mathrm{GPa}$ & $\overline{65} \pm 8$ & 62.3 & \multirow{3}{*}{ ASTM D3039 } \\
\hline Tensile strength weft & RT/dry & $\mathrm{MPa}$ & $\geq 500$ & 557 & \\
\hline Tensile modulus weft & RT/dry & $\mathrm{GPa}$ & $65 \pm 8$ & 60.9 & \\
\hline Compression strength warp & RT/dry & $\mathrm{MPa}$ & $\geq 300$ & 509 & \multirow{4}{*}{ ASTM D6641 } \\
\hline Compression modulus Warp & RT/dry & $\mathrm{GPa}$ & $5 \overline{8} \pm 8$ & 61.2 & \\
\hline Compression strength Weft & RT/dry & $\mathrm{MPa}$ & $\geq 280$ & 362 & \\
\hline Compression modulus weft & RT/dry & $\mathrm{GPa}$ & $5 \overline{7} \pm 8$ & 57.7 & \\
\hline Bending strength warp & RT/dry & $\mathrm{MPa}$ & $\geq 650$ & 883 & \multirow{2}{*}{ ASTM D790 } \\
\hline Bending modulus warp & RT/dry & $\mathrm{GPa}$ & $\overline{58} \pm 8$ & 56.8 & \\
\hline Short bean shear strength & RT/dry & $\mathrm{MPa}$ & $\geq 50$ & 55.7 & ASTM D2344 \\
\hline In plane shear strength & RT/dry & $\mathrm{MPa}$ & $\geq 45$ & 72.6 & \multirow{2}{*}{ ASTM D3518 } \\
\hline In plane shear modulus & RT/dry & $\mathrm{GPa}$ & $3 . \overline{5} \pm 1$ & 3.84 & \\
\hline
\end{tabular}

Table 3. Mechanical properties of AGMP3600/A38 (carbon fiber, twill fabric, $200 \mathrm{~g} / \mathrm{m}^{2}, 42 \mathrm{vol} \%$ ), a rosin-epoxy laminate, under a hydrothermal condition of $1000 \mathrm{~h} / 70{ }^{\circ} \mathrm{C} / 85 \% \mathrm{r.H}$.

\begin{tabular}{|c|c|c|c|c|c|c|}
\hline \multirow{2}{*}{$\begin{array}{c}\text { Properties } \\
\text { ply thickness }\end{array}$} & \multirow{2}{*}{$\begin{array}{l}\text { Unit } \\
\mathrm{mm}\end{array}$} & \multirow[t]{2}{*}{ Humidity } & \multicolumn{2}{|c|}{ Temperature $/{ }^{\circ} \mathrm{CReference}^{1}$} & \multirow{2}{*}{$\begin{array}{c}\text { AGMP3600/A38 } \\
0.265 \\
\end{array}$} & \multirow[t]{2}{*}{ Standard } \\
\hline & & & - & 0.26 & & \\
\hline \multirow{4}{*}{$\begin{array}{c}\text { Flexural } \\
\text { strength warp }\end{array}$} & \multirow{4}{*}{$\mathrm{MPa}$} & & -55 & - & 949 & \multirow{8}{*}{ ASTMD 790-03 } \\
\hline & & dry & RT & - & 947 & \\
\hline & & & 70 & - & 903 & \\
\hline & & $70^{\circ} \mathrm{C} /$ wet $85 \%$ & 70 & - & 826 & \\
\hline \multirow{4}{*}{$\begin{array}{c}\text { Flexural } \\
\text { modulus warp }\end{array}$} & \multirow{4}{*}{$\mathrm{GPa}$} & & -55 & - & 50.9 & \\
\hline & & dry & RT & - & 51.4 & \\
\hline & & & 70 & - & 58.7 & \\
\hline & & $70{ }^{\circ} \mathrm{C} /$ wet $85 \%$ & 70 & - & 51.8 & \\
\hline \multirow{4}{*}{$\begin{array}{l}\text { Interlaminar } \\
\text { shear strength } \\
\text { warp }\end{array}$} & \multirow{4}{*}{$\mathrm{MPa}$} & & -55 & 65 & 62.4 & \multirow{4}{*}{$\begin{array}{c}\text { ASTMD } \\
\text { 2344/D2344M-00(2006) }\end{array}$} \\
\hline & & dry & $\mathrm{RT}$ & 60 & 74.8 & \\
\hline & & & 70 & 40 & 65.3 & \\
\hline & & $70^{\circ} \mathrm{C} /$ wet $85 \%$ & 70 & 19 & 46.4 & \\
\hline \multirow{4}{*}{$\begin{array}{l}\text { Tensile strength } \\
\text { warp }\end{array}$} & \multirow{4}{*}{$\mathrm{MPa}$} & & -55 & 500 & 618 & \multirow{9}{*}{$\begin{array}{c}\text { ASTMD } \\
\text { 3039/D3039M-e1 }\end{array}$} \\
\hline & & dry & RT & 625 & 667 & \\
\hline & & & 70 & 590 & 714 & \\
\hline & & $70^{\circ} \mathrm{C} /$ wet $85 \%$ & 70 & 560 & 674 & \\
\hline \multirow{4}{*}{$\begin{array}{l}\text { Tensile modulus } \\
\text { warp }\end{array}$} & \multirow{4}{*}{ GPa } & & -55 & $52 \pm 6$ & 55.25 & \\
\hline & & dry & RT & $52 \pm 6$ & 54.6 & \\
\hline & & & 70 & $52 \pm 6$ & 53 & \\
\hline & & $70^{\circ} \mathrm{C} /$ wet $85 \%$ & 70 & $52 \pm 6$ & 49 & \\
\hline Poisson ratio & - & dry & RT & $0.05 \pm 0.005$ & 0.052 & \\
\hline \multirow{4}{*}{$\begin{array}{l}\text { Compression } \\
\text { strength warp }\end{array}$} & \multirow{4}{*}{$\mathrm{MPa}$} & & -55 & 600 & 758 & \multirow{8}{*}{$\begin{array}{c}\text { ASTMD } \\
6641 / \mathrm{D} 6641 \mathrm{M}-14\end{array}$} \\
\hline & & dry & RT & 535 & 651 & \\
\hline & & & 70 & 430 & 630 & \\
\hline & & $70^{\circ} \mathrm{C} /$ wet $85 \%$ & 70 & 310 & 605 & \\
\hline \multirow{4}{*}{$\begin{array}{l}\text { Compression } \\
\text { modulus warp }\end{array}$} & \multirow{4}{*}{ GPa } & & -55 & $46 \pm 6$ & 52.5 & \\
\hline & & dry & RT & $46 \pm 6$ & 53 & \\
\hline & & & 70 & $46 \pm 6$ & 52.5 & \\
\hline & & $70^{\circ} \mathrm{C} /$ wet $85 \%$ & 70 & $46 \pm 6$ & 55 & \\
\hline \multirow{4}{*}{$\begin{array}{l}\text { In plane shear } \\
\text { strength }\end{array}$} & \multirow{4}{*}{$\mathrm{MPa}$} & & -55 & 100 & 136 & \\
\hline & & dry & RT & 95 & 114 & \\
\hline & & & 70 & 80 & 96.8 & \\
\hline & & $70{ }^{\circ} \mathrm{C} /$ wet $85 \%$ & 70 & 60 & 89 & ASTMD \\
\hline & & & -55 & $4.5 \pm 0.35$ & 4.74 & 3518/D3518M-94 \\
\hline In plane shear & & dry & RT & $3.65 \pm 0.35$ & 4.21 & \\
\hline modulus & GPa & & 70 & $3.5 \pm 0.35$ & 2.63 & \\
\hline & & $70{ }^{\circ} \mathrm{C} /$ wet $85 \%$ & 70 & $1.25 \pm 0.35$ & 2.75 & \\
\hline
\end{tabular}


Table 3. Cont.

\begin{tabular}{ccccccc}
\hline Properties & Unit & Humidity & Temperature ${ }^{\circ}$ CReference $^{1}$ & AGMP3600/A38 & Standard \\
\hline $\begin{array}{c}\text { CAI (lay up } \\
(+/ 0 /-/ 90) 2 \mathrm{~s}, \\
\text { energy 25 J }\end{array}$ & MPa & dry & RT & 180 & 185 & ASTMD 7136/7137 \\
\hline $\begin{array}{c}\text { Filled hole } \\
\text { tension strength }\end{array}$ & $\mathrm{MPa}$ & dry & RT & 180 & 317 & ASTMD3518 \\
\hline $\begin{array}{c}\text { Filled hole } \\
\text { compression } \\
\text { strength }\end{array}$ & $\mathrm{MPa}$ & dry & RT & 250 & $\begin{array}{c}\text { no destroy, } \\
\text { displacement } \\
4 \text { mm }\end{array}$ & ASTMD6742 \\
\hline
\end{tabular}

${ }^{1}$ A commercial product.

Table 4. Mechanical properties of AGMP5600/EW250F (glass fabric, 8 satin, $47 \mathrm{vol} \%$ ), a $180{ }^{\circ} \mathrm{C}$ cure rosin-sourced epoxy laminate, under different hydrothermal conditions.

\begin{tabular}{|c|c|c|c|c|}
\hline Mechanical Properties & Unit & Test Condition & Reference $^{1}$ & AGMP5600/EW250F \\
\hline ply thickness & $\mathrm{mm}$ & - & 0.26 & 0.265 \\
\hline \multirow{4}{*}{ Flexural strength warp } & \multirow{4}{*}{$\mathrm{MPa}$} & -55 & - & 864 \\
\hline & & RT & - & 687 \\
\hline & & 70 & - & 650 \\
\hline & & $70{ }^{\circ} \mathrm{C} /$ wet $85 \%$ & - & 431 \\
\hline \multirow{4}{*}{ Flexural modulus warp } & \multirow{4}{*}{$\mathrm{GPa}$} & -55 & - & 21.4 \\
\hline & & RT & - & 23.4 \\
\hline & & 70 & - & 22 \\
\hline & & $70{ }^{\circ} \mathrm{C} /$ wet $85 \%$ & - & 22.2 \\
\hline \multirow{4}{*}{ Interlaminar shear strength warp } & \multirow{4}{*}{$\mathrm{MPa}$} & -55 & 88 & 74.6 \\
\hline & & RT & 68 & 59.1 \\
\hline & & 70 & 59 & 49 \\
\hline & & $70{ }^{\circ} \mathrm{C} /$ wet $85 \%$ & 39.6 & 48.3 \\
\hline \multirow{4}{*}{ Tensile strength warp } & \multirow{4}{*}{$\mathrm{MPa}$} & -55 & 500 & 573 \\
\hline & & RT & 410 & 510 \\
\hline & & 70 & 330 & 460 \\
\hline & & $70{ }^{\circ} \mathrm{C} /$ wet $85 \%$ & 315 & - \\
\hline \multirow{4}{*}{ Tensile modulus warp } & \multirow{4}{*}{$\mathrm{GPa}$} & -55 & $27 \pm 6$ & 23.9 \\
\hline & & RT & $24 \pm 6$ & 24.4 \\
\hline & & 70 & $24 \pm 6$ & 22.3 \\
\hline & & $70{ }^{\circ} \mathrm{C} /$ wet $85 \%$ & $24 \pm 6$ & - \\
\hline \multirow{4}{*}{ Compression strength warp } & \multirow{4}{*}{$\mathrm{MPa}$} & -55 & 800 & 589 \\
\hline & & RT & 660 & 456 \\
\hline & & 70 & 550 & 397 \\
\hline & & $70{ }^{\circ} \mathrm{C} /$ wet $85 \%$ & 470 & 384 \\
\hline \multirow{4}{*}{ Compression modulus warp } & \multirow{4}{*}{$\mathrm{GPa}$} & -55 & $26 \pm 3$ & 26.7 \\
\hline & & RT & $25 \pm 3$ & 25.8 \\
\hline & & 70 & $25 \pm 3$ & 24 \\
\hline & & $70{ }^{\circ} \mathrm{C} /$ wet $85 \%$ & $25 \pm 3$ & 24.7 \\
\hline \multirow{4}{*}{ In plane shear strength } & \multirow{4}{*}{$\mathrm{MPa}$} & -55 & 110 & 113 \\
\hline & & RT & 85 & 90 \\
\hline & & 70 & 88 & 71 \\
\hline & & $70{ }^{\circ} \mathrm{C} /$ wet $85 \%$ & 77 & 56.4 \\
\hline \multirow{4}{*}{ In plane shear modulus } & \multirow{4}{*}{$\mathrm{GPa}$} & -55 & $5.7 \pm 1$ & 4.8 \\
\hline & & RT & $4.8 \pm 1$ & 3.26 \\
\hline & & 70 & $3.9 \pm 1$ & 3.1 \\
\hline & & $70{ }^{\circ} \mathrm{C} /$ wet $85 \%$ & $3.5 \pm 1$ & 3.13 \\
\hline
\end{tabular}

${ }^{1}$ A commercial product.

\section{Epoxy Resins Based on Itaconic Acid}

Itaconic acid, which is also referred to as methylenesuccinic acid, is typically produced through the fermentation of carbohydrates such as glucose or starch using Aspergillus terreus. Given its strong capacity to replace petrochemicals in the chemical industry, it has been selected as one of the top 12 potential bio-based platform chemicals by the U.S. Department of Energy [9]. To the best of our 
knowledge, it has been widely used in the production of styrene-butadiene-acrylonitrile and acrylate latex in the paper and coating sectors.

Epoxy (EP) resin derived from itaconic acid, designated in the paper as EIA, can be synthesized following the synthetic route shown in Scheme 2. To evaluate its properties, EIA and commercial DGEBA (diglycidyl ether of bisphenol A, epoxide equivalent weight of 182-192 g/eq.) were cured with methyl hexahydrophthalic anhydride (MHHPA), respectively. The results show that EIA presented higher epoxide (0.625) and higher reactivity values than DGEBA. Relative to DGEBA, the cured EIA showed comparable or higher tensile strength $(87.5 \mathrm{MPa})$, elongation at break $(7.1 \%)$, flexural strength $(152.4 \mathrm{MPa})$ and modulus $(3430.8 \mathrm{MPa})$, and glass transition temperature $\left(\mathrm{Tg}=130{ }^{\circ} \mathrm{C}\right)$. In addition, after co-monomers such as divinyl benzene (DVB) and acrylated epoxidized soybean oil (AESO) were introduced into the EIA/MHHPA system, dual-curing systems were formed, and the rigidity and toughness could be manipulated further via the various contents of rigid DVB or soft AESO, as shown in Figure 4, compared with data from reference published [10].

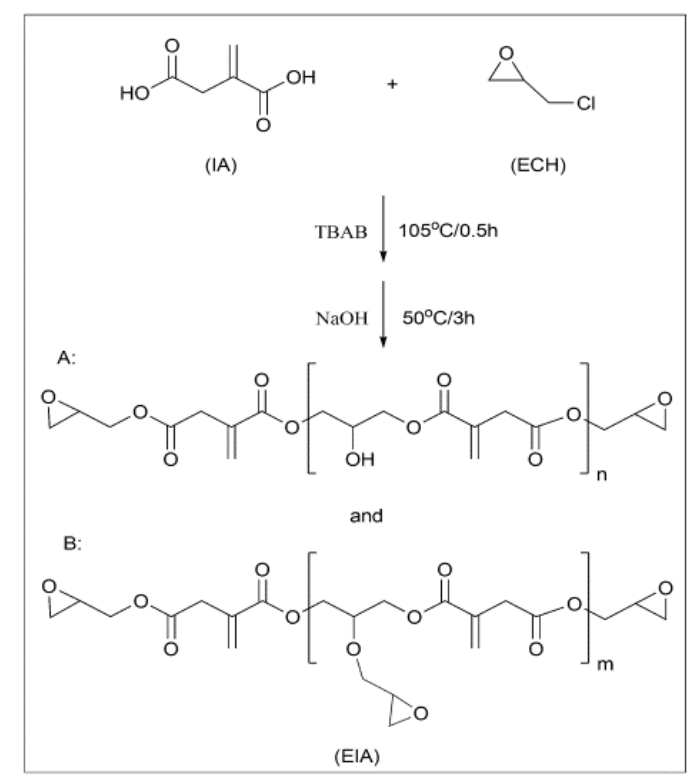

Scheme 2. Synthetic route and chemical structures of itaconic-acid-based epoxy resin (EIA).
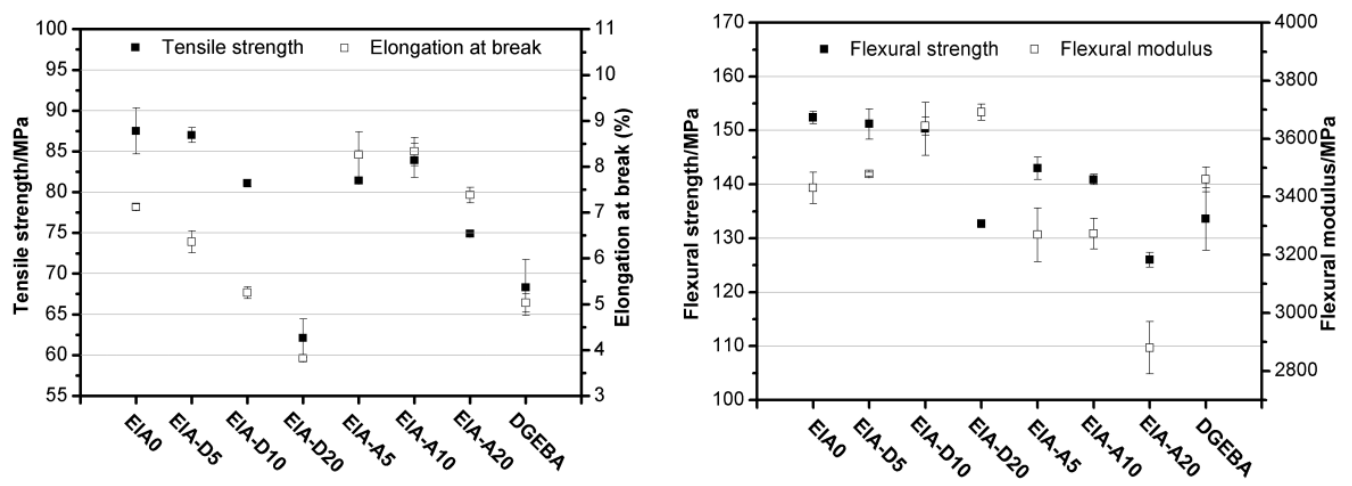

Figure 4. Mechanical properties of the cured EP resins. EIA0 and DGEBA refer to the cured samples without comonomers; D and A denote the DVB (divinyl benzene) and AESO (acrylated epoxidized soybean oil) co-monomers, respectively.

As shown in Scheme 3, direct reactions between itaconic acid and epichlorohydrin generate resin EIA, which is a mixture of different oligomers of varying molecular weights. To make the best use of the 
carboxyl groups and itaconic acid double bond, a trifunctional EP monomer (TEIA) was designed and synthesized (Figure 4), and it generated an extremely high epoxide value of 1.16 and a low viscosity of $0.92 \mathrm{~Pa}$ s at $25^{\circ} \mathrm{C}$. It is well known that low resin viscosities are beneficial for manufacturing. The lower viscosities in TEIA render it easier to process than DGEBA. In Table 5, the flexural properties of TEIA cured by different curing agents are listed. When flexible poly(propylene glycol) bis(2-aminopropyl ether) (D230) is used as the curing agent, the TEIA/D230 system shows higher flexural modulus, higher strain at break and comparable flexural strength to DGEBA/D230. When rigid MHHPA was employed as the curing agent, the flexural strength, modulus and elongation at break of the TEIA/MHHPA system exceeded those of the DGEBA/MHHPA system. These results denote that TEIA may be used as a high-performance epoxy resin [11].<smiles>C=CCOC(=O)C(C)CC(=O)OCC=C[C@@H]1O[C@H]1COC(=O)CC1(C(=O)OCC2CO2)CO1</smiles>

Scheme 3. Synthesis of the trifunctional epoxy resin of itaconic acid (TEIA).

Table 5. Flexural properties of cured EP resins with D230 curing agents.

\begin{tabular}{cccc}
\hline Samples & Flexural Strength (MPa) & Flexural Modulus (MPa) & Elongation at Break (\%) \\
\hline DGEBA/D230 & $121 \pm 1$ & $2952 \pm 18$ & $13 \pm 2$ \\
TEIA/D230 & $117 \pm 2$ & $3603 \pm 77$ & $21 \pm 1$ \\
\hline
\end{tabular}

Given the presence of double bonds in itaconic acid and the low flame retardancy of EP resins, a flame-resistant DOPO (6H-dibenz $(\mathrm{C}, \mathrm{E})(1,2)$ oxaphosphorin-6-oxide) was chemically incorporated into the itaconic-acid-based EP resin, and a phosphorus-containing EP resin (EADI) was obtained (Scheme 4). The property study showed that the cured EADI network presents a comparable glass transition temperature and mechanical properties to those of the DGEBA system. In addition, excellent flame retardancy capacities with the UL94 V-0 grade used during vertical burning tests were observed for the EADI system. EADI may be used as a bio-based candidate for EP flame retardancy [12].

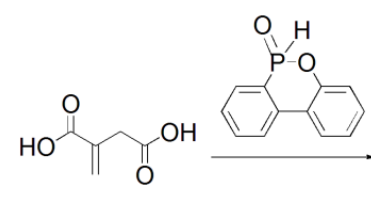

IA

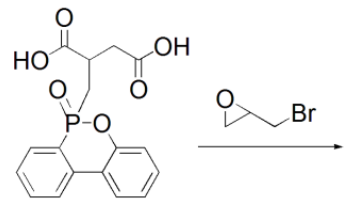

DI<smiles>O=C(CC(CC(=O)OCC1CO1)P(=O)(OCC1CO1)Oc1ccccc1-c1ccccc1)OCC1CO1</smiles>

EADI

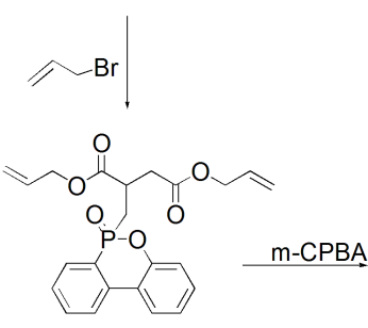

ADI

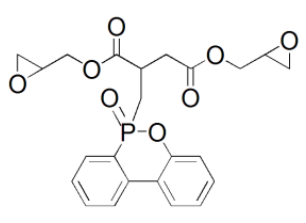

EADI

Scheme 4. Synthetic route of phosphorus-containing itaconic-acid-based epoxy resin. 


\section{Trial Manufacturing and Demonstration}

With the promising properties, as one of the project targets, biocomposites were trial-manufactured to produce interior and quasi-structural parts for potential application in airplane and ground transportation vehicles. Figure 5 is an illustration of an interior side panel made of AGMP3600, the rosin-sourced EP, with a honeycomb sandwich core for a MA600 airplane. The side panel was manufactured using AGMP3600 prepregs in an autoclave. The composite panels are strong, lightweight, fire resistant, decorative, and impervious to mold and insects. Structure-decoration integration methods can clearly support to the production of identical or even more complex composite parts while simultaneously presenting mechanical and structural damping advantages in various applications.
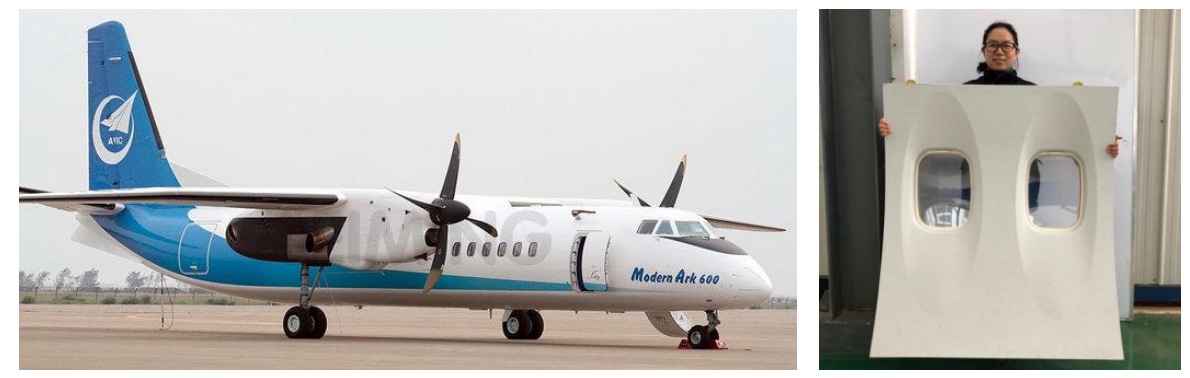

Figure 5. MA600 airplane and the composite side panel made of AGMP3600/honeycomb sandwich composites (Photos courtesy of Fangbo Ding, AVIC XAC, Commercial Aircraft Co., Ltd.).

Figure 6 shows an electric race car in cooperation with Tsinghua University, China. In this case, the rosin-sourced epoxy composite was used to produce the carbon composite body with a honeycomb core. The process also used AGMP3600 prepreg. The strong conforming capacities of the materials along the curved contour were well-demonstrated. A manufacturing benefit of the biocomposites cured in an autoclave pertains to their full compatibility with the standard industrial production processes.

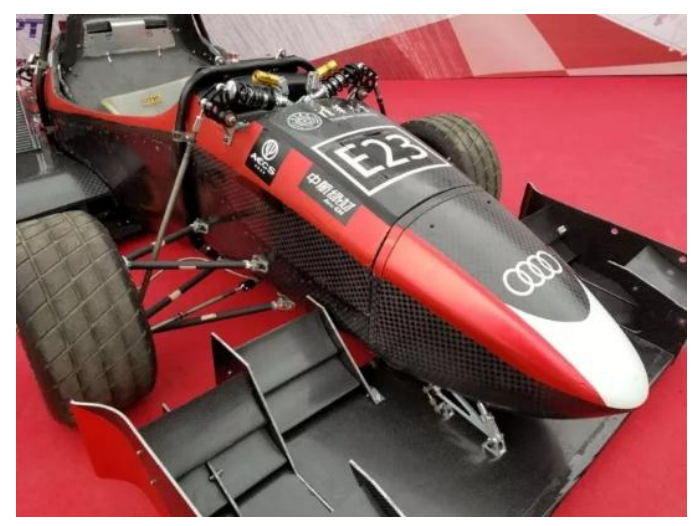

Figure 6. Electric race car, its body was manufactured using AGMP3600/honeycomb sandwich composites.

\section{Conclusions}

1. Rosin-sourced anhydride was developed and used as a hardener for epoxy to formulate a matrix resin with an imidazole-type latent catalyst for biocomposites. The mechanical properties of the biocomposites with the rosin-epoxy as matrix resins were tested, also under hydrothermal conditions. It was shown that the mechanical properties were generally comparable to the state-of-the-art, petroleum-sourced counterpart materials, but yielded a higher glass transition temperature. 
2. Epoxy resin derived from itaconic acid was also synthesized. It showed comparable or higher mechanical properties and glass transition temperatures compared to a common counterpart. A phosphorus-containing epoxy was also developed by incorporating DOPO into the itaconic acid EP to formulate a flame-retardant resin system.

3. Using the rosin epoxy system, which is technologically more mature than the itaconic system, quasi-structural plant fiber reinforced components were manufactured and demonstrated for aircraft and ground transportation vehicles. The process condition was found to be fully compatible with standard industrial processes.

Author Contributions: X.Y. conceived and guided the project and study; X.Z. performed the formulation of the resins; F.D. and J.T. were responsible for the manufacturing of the structural parts.

Funding: The study was partially supported by the Chinese MIIT Special Research Program under Grant No. MJ-2015-H-G-103 and the European Union's Horizon 2020 Research and Innovation Program under Grant Agreement No. 690638. They are greatly acknowledged.

Acknowledgments: The authors are thankful to Xiaoqing Liu, Songqi Ma and Jin Zhu, NIMTE-CAS (Ningbo Institute of Materials and Technology Engineering, Chinese Academy of Sciences), for supplying the rosin-sourced polymers and related information.

Conflicts of Interest: The authors declare no conflict of interest.

\section{References}

1. Yi, X.; Li, Y. Bio-Sourced Resins, Plant Fibers and Biocomposites; China Construction Industry Press: Beijing, China, 2017. (In Chinese)

2. Powers, W.F. Automotive Materials in the 21st Century. Adv. Mater. Process. 2000, 157, 38-41.

3. Drzal, L.T.; Mohanty, A.K.; Misra, M. Bio-composite materials as alternatives to Petroleum-based composites for automotive applications. In Composite Materials and Structures Center; Michigan State University: East Lansing, MI, USA, 2000.

4. ECO-COMPASS. Available online: http:// www.eco-compass.eu (accessed on 30 June 2016).

5. Coppen, J.J.W.; Hone, G.A. Gum naval stores: Turpentine and rosin from pine resin. In NON-WOOD FOREST PRODUCTS 2; Natural Resources Institute, Ed.; Food and Agriculture Organization of the United Nations: Rome, Italy, 1995; p. 4. ISBN 92-5-103684-5.

6. Liu, X.; Yi, X.; Zhu, J. Bio-based epoxies and composites as environmentally friendly alternative materials. In Thermosets: Structure, Properties and Applications, 2nd ed.; Guo, Q., Ed.; Elsevier: Amsterdam, The Netherlands, 2017; pp. 621-636. ISBN 978-0-08-101021-1.

7. Zhang, X.; Wu, Y.; Wei, J.; Tong, J.; Yi, X. Curing kinetics and mechanical properties of bio-based composite using rosin-sourced anhydrides as curing agent for hot-melt prepreg. Sci. China Technol. Sci. 2017, 60, 1318-1331. [CrossRef]

8. Lu, Y.; Zhao, Z.; Bi, L.; Chen, Y.; Wang, J.; Xu, S. Synthesis of a multifunctional hard monomer from rosin: The relationship of allyl structure in maleopimarate and UV-curing property. Sci. Rep. 2018, 8, 2399. [CrossRef] [PubMed]

9. Werpy, T.; Petersen, G. Top Value Added Chemicals from Biomass. In Volume I-Results of Screening for Potential Candidates from Sugars and Synthesis Gas; The National Renewable Energy Laboratory (NREL) Report DOE/GO-102004-1992; U.S. Department of Energy: Washington, DC, USA, 2004.

10. Ma, S.; Liu, X.; Jiang, Y.; Tang, Z.; Zhang, C.; Zhu, J. Bio-based epoxy resin from itaconic acid and its thermosets cured with anhydride and comonomers. Green Chem. 2013, 15, 245-254. [CrossRef]

11. Ma, S.; Liu, X.; Fan, L.; Jiang, Y.; Cao, L.; Tang, Z.; Zhu, J. Synthesis and Properties of a Bio-Based Epoxy Resin with High Epoxy Value and Low Viscosity. ChemSusChem 2014, 7, 555-562. [CrossRef] [PubMed]

12. Ma, S.; Liu, X.; Jiang, Y.; Fan, L.; Feng, J.; Zhu, J. Synthesis and properties of phosphorus-containing bio-based epoxy resin from itaconic acid. Sci. China-Chem. 2014, 57, 379-388. [CrossRef] 